\title{
Summary of the Modern Wheel Slip Controller Principles
}

\author{
Petr Pichlík ${ }^{1)}$ \\ 1) CTU in Prague, FEE, Department of Electric Drives and Traction, Prague, Czech Republic, e-mail: \\ pichlpet@fel.cvut.cz.
}

\begin{abstract}
Railway traction vehicles need to transfer high tractive effort from wheels to rails. The task is complicated because the maximum transferable force continuously changes during the train run, and the change can lead to the high wheels slip velocity or slippage. The effects are undesirable and must be prevented if it is possible or at least limited by slip controllers. There have been several slip controllers developed based on different principles with different degree of complexity and efficiency. The paper summarises principles of the slip control methods and brings their overview with the simulation of their behaviour.
\end{abstract}

Keywords - adhesion, railway, traction, wheel slip control.

\section{INTRODUCTION}

The modern railway vehicles can transport a large number of cargo or passengers to long distance. To be possible to reach the high tractive effort that is required by cargo trains or high speed required by passengers trains the force from wheels to rails have to be transferred effectively. The requirement is obvious, but due to the steel contact areas between wheels and rails, it can be challenging to fulfil it, especially during bad weather because the force that can be transmitted between wheels and rails depends on the adhesion that is closely linked with the rails surface conditions thus with the weather. The locomotives are designed to fully utilise all available adhesion during good conditions when the adhesion coefficient has a high value. However, when the conditions become worse, the locomotive can produce higher tractive force than the force that can be transferred by the wheel-rail contact. If the force is not limited, the slippage of the wheels is the result in the case. The slippage is undesirable because it increases wear of wheels and rails [1] and can damage mechanical parts of the locomotive bogie in the worst cases. Once slippage is created, it must be suppressed by the massive tractive force decrease. If the force is decreased many times, the train can gain delay [2] or even suck at the track. The problem was solved by the gradual development of many types of slip controllers. The early controllers were protections that eliminate the slippage if it occurs. The modern ones can prevent slippage occurrence by early regulatory intervention. The problem with the force transfer have all railway vehicles not only locomotives. However, other railway traction vehicles like multiple units have a higher number of driven wheelsets and reach lower force. Therefore, their maximum force requires lower adhesion, and the slippage occurs when the rails surface conditions are very adverse.

The slip controllers for railway traction vehicles are developed for many decades, and their development still continues. The new or improved slip controllers are developed because the slip control problem is not sufficiently solved. The slip controller basic purpose is to enable the maximum force transfer by the wheel-rails contact area if the required force is higher than the maximum transferable force due to an adhesion limitation. The slip controller must also keep the slip velocity, i.e. difference between wheel circumference velocity and its longitudinal velocity, at an acceptable value to limit wear of wheels and rails. Therefore, the slip controller has to change the required tractive force to fulfil the requirements continuously. Moreover, to the modern slip controllers are put new demands like suspension of torsional vibrations that occur in the wheelset mechanical system, and the torsional vibrations amplitude is connected with the adhesion. Although the slip controllers are developed for decades, their summary is missing, or it is incomplete. Therefore, the paper summarises the most common slip controller principles and describes modern and perspective slip controllers in more detail.

The rest of the paper is organised as follows. The adhesion phenomenon and its influence to the tractive force transfer by the wheel-rail contact are described in the next chapter because the adhesion is essential for the slip controller operation and design. The slip controllers overview and detailed description of the most used is described next. Finally, the simulation of the selected slip controllers is described.

\section{ADHESION AND FORCES}

The adhesion is crucial for the tangential force transfer between wheels and rails during traction or braking. Therefore the description of the slip controllers is preceded the description of the adhesion. The tangential force can be expressed as follows.

$$
F_{\mathrm{T}}=\mu \cdot W \cdot g
$$

Where $F_{\mathrm{T}}$ is a tangential force, $\mu$ is an adhesion coefficient, $W$ is an adhesion weight, and $g$ is the gravity acceleration.

The value of the adhesion coefficient depends on many parameters like wheel slip velocity, train longitudinal velocity and conditions on rails surface. The slip velocity is a difference between the wheel circumference velocity and its longitudinal velocity. The circumference velocity can be measured by incremental encoders mounted on wheels or motor. However, to determine the longitudinal velocity is difficult when all wheels are driven, and the velocity has to be calculated by some averaging or has to be estimated in this case. The slip velocity is necessary for the tangential force transmission between the wheel and the rail. Therefore, every driven or braked wheel has to 
have different circumference velocity from its longitudinal velocity, thus slip velocity [3]. Examples of the dependence of the adhesion coefficient on the slip velocity for different adhesion conditions are depicted in Fig. 1 and wheel with depicted forces and velocities are depicted in Fig. 2. The adhesion characteristic can be divided into the two areas from the electric drive control point of view. The first area of the characteristic is called a stable area, and the area is from zero value of the slip velocity to approximately $2 \mathrm{~km} \cdot \mathrm{h}^{-1}$ [4]. The area is called stable because the slip controller can work in the area without any controller reaction. An unstable area is located behind the stable area. Between the areas is located the maximum point of the characteristic. The maximum point moves to higher slip velocities and lowers adhesion coefficient values when the rail surface conditions are getting worse. The goal of the slip controller is to keep the slip velocity in the stable area in passenger trains or multiple units case and the stable area or not far from the peak value in the unstable area in freight trains [5].

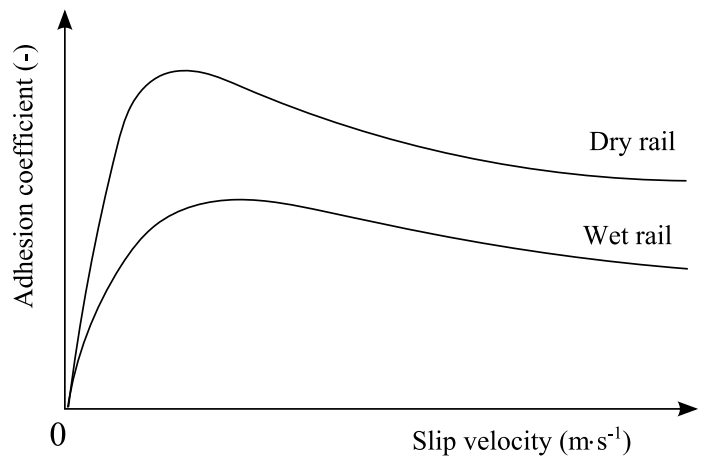

Fig. 1 Example of the adhesion characteristics for different rail surface conditions

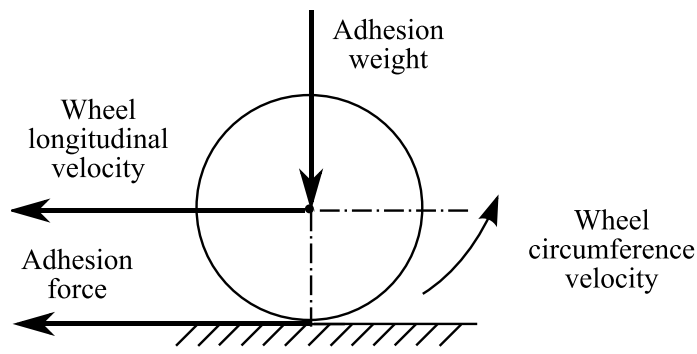

Fig. 2 Wheel and applied forces and velocities

From the previous description, it is clear that the slip velocity affects the value of the actual adhesion coefficient from zero to the maximum value. However, the conditions of the rail surface, train velocity and temperature affect the maximum value of the adhesion coefficient and position of the maximum point on the adhesion characteristic. The influence of the rail surface conditions are random and cannot be predicted. The adhesion coefficient can reach values from 0.05 to 0.4 due to the rail surface changes [6]. Moreover, the adhesion changes approximately every few meters even when the wheatear is unchangeable. On the other hand, the effect of the velocity is described by wellknown Curtius and Kniffler formula [6]. The maximum value of the adhesion coefficient decreased with increased velocity according to the formula.

The second parameter from (1) that affects the value of the tangential force is the adhesion weight. The value of the adhesion weight changes when the dynamic motions of the locomotive occur e.g. pitches or bounces. These phenomena are related to the locomotive mechanical parameters, values of the tractive effort, load, changes of the tractive effort and track parameters.

\section{SLIP CONTROLLERS}

The slip control methods can be sorted into several groups according to their principle of operation [7] or target railway vehicle [5], but not exactly given slip control methods classification is presented in the literature. Generally, the slip control methods can be sorted into a forerunner of the modern slip controllers to the re-adhesion controllers and the slip controllers with different level of regulation quality and principles [8]. Proposed slip control methods classification that takes into account the methods evolutionary and principle of the operation is depicted in Fig. 3. Some of the methods from the picture are also described in [9] in detail.

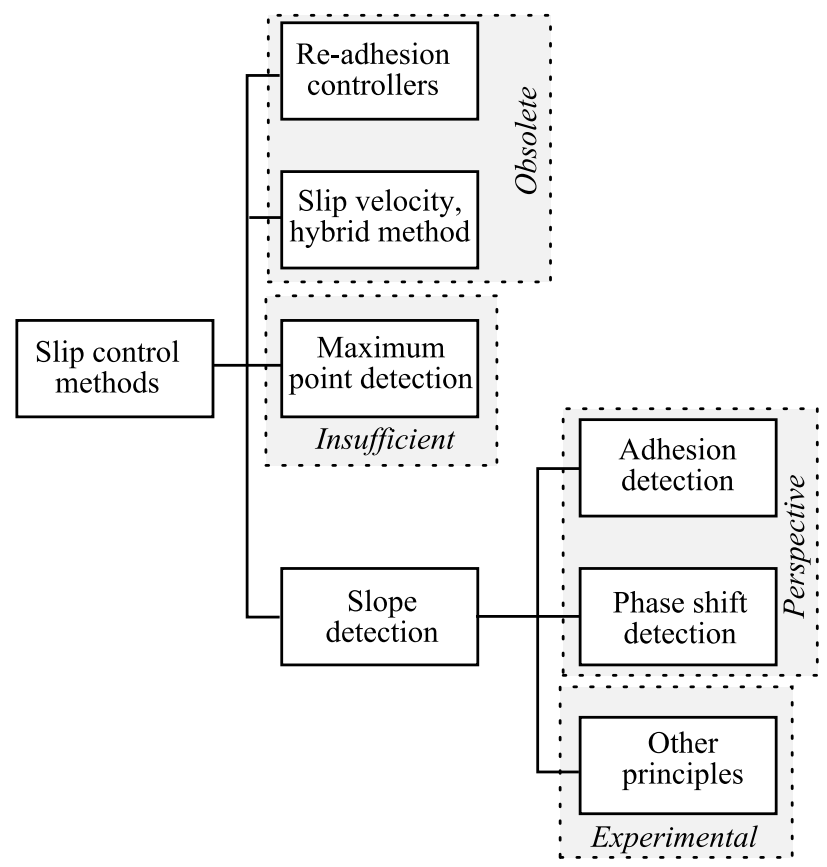

Fig. 3 Proposed slip control methods sortation

The first of the slip control methods were re-adhesion controllers. The re-adhesion controllers work as a protection against the slippage when it occurs. They are typically based on the slip velocity comparison with a fixed predefined threshold. If the threshold is overstepped, the controller steeply decreases the tractive force. Another re-adhesion controller is based on the wheel acceleration comparison with a predefined threshold. These methods can simply fail due to slow slippage creation or by slippage of all wheelset. Another principle is based on the voltage or current difference between serially or in parallel connected motors. If the difference occurs, one wheelset is in slippage. The re-adhesion controllers cannot prevent the slippage creation and can only limit it. The re-adhesion controllers steeply decrease the tractive force when the slippage is detected, and after slippage suppression, it starts the force increase to the initial level. This behaviour often leads to another slippage creation, and the locomotive driver must decrease the required tractive force to prevent another slippage creation. 
From the re-adhesion controllers, the first slip controllers were developed. This slip controllers control the slip velocity to a constant value. The value of the required slip velocity is set as the higher acceptable value on which slippage does not occur. The slip controller main disadvantage is low adhesion utilisation, and the slip velocity calculation is also problematic. The slip controller is often improved about acceleration protection to create a hybrid slip controller [10]. These slip controllers can be used as additional protection to the modern slip controllers to work as protection when they potentially fail.

The modern slip controllers try to avoid slippage formation by preventive and continuous regulatory interventions. The modern slip controllers are based on the determination of the actual adhesion characteristic parameters. The determined parameters can be the maximum point location on the actual adhesion characteristic or slope of the actual characteristic. Moreover, the slip controller can be sorted according to the adhesion or slip detection mechanism. The slip controllers based on the slope determination requires knowledge of the adhesion parameters like adhesion coefficient or adhesion force. However, none of these parameters can be directly measured during train runs. Therefore, the slip controllers use estimation techniques to determine the value. The estimators can be disturbance observer [11] or some variant of the Kalman filter [12]. The different way how to determine the slope is based on a mechanical phenomenon that occurs in the torque transfer chain between electric motor and wheels, i.e. determination of a phase shift between motor torque and its velocity [13] or according to torsional vibrations [14].

Slip controllers that detect a maximum point position [15] can fully utilise the whole available adhesion, but they must permanently work in the unstable area of the adhesion characteristic. Therefore, the slip controllers require a highly dynamic electric drive. The main disadvantage of the slip controllers based on the principle is that they can cause some undesirable mechanical effects that are connected with stick-slip oscillations that occur when the operating point moves from the stable area to the unstable area and back [16].

There are also exists other slip controllers based on different principles described in the literature. Methods that evaluate noise [17], or use a Hilbert-Huang transformation [18]. However, the approaches are experimental.

The explanation of the main difference between the selected principles of the slip controllers is depicted in Fig. 4. The figure shows a set of adhesion characteristics for different conditions of the surface of the rails and the positions of the operating points for different slip controllers principles when the maximum force has to be transferred. The simple slip controller control slip velocity to a constant can optimally work with the good adhesion characteristic. On the other hand, the modern slip controllers can work near the maximum point with good adhesion characteristic. However, the slip controller based on the adhesion characteristic slope detection as the only one can work with acceptable slip velocity value when the adhesion is adverse because the method that controls to the maximum point moves the operating point to unacceptable higher slip velocities when the adhesion is adverse.

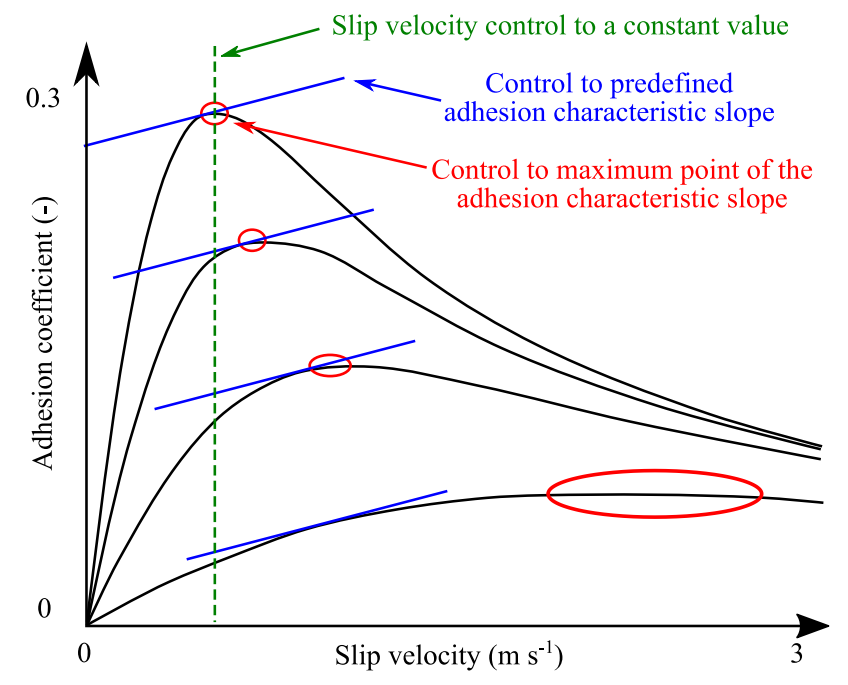

Fig. 4 Slip controllers principles comparison

\section{A. Adhesion Characteristic Slope Determination}

Because the slip controllers that estimates the adhesion characteristic slope is perspective, the principles of the slip controller are described in more detail in the subchapter. This group of methods is based on two different approaches. The first approach uses the adhesion estimation by a proper estimator according to slip velocity and applied force change. The second approach estimates adhesion according to the phase shift between motor angular velocity and wheel angular velocity.

The slip controllers that estimates the adhesion characteristic slope according to adhesion estimation typically estimates the adhesion coefficient or force adhesion force and calculate a derivative of the adhesion force $F_{\mathrm{A}}$ and the slip velocity $v_{\mathrm{s}}$. The derivative can be calculated as follows:

$$
\frac{\mathrm{d} F_{\mathrm{A}}}{\mathrm{d} v_{\mathrm{S}}}=0
$$

When (2) is met, the operating point is located in the maximum point of the adhesion characteristic. If the derivative is positive, the operating point is located in the stable area of the characteristic, and if the derivative is negative, the operating point is located in the unstable area of the characteristic. The slip controller can basically detect the maximum point of the adhesion characteristic. However, the controller structure has to be highly dynamic, and the usage of the speed controller is recommended. However, the speed controller is not a standard part of the locomotive control structure, and it would have to be installed.

The possible estimators can be disturbance observers or the proper variant of the Kalman filter. The typically used disturbance observers are zero order, first order or full order. The difference between the observer orders lays in its complexity and accuracy. The simple disturbance observers can sometimes have problems with proper function [19]. More accurate results can be achieved by using a Kalman filter, extended Kalman filter or unscented Kalman filter [20]. The adhesion coefficient can also be estimated according to a wheel-rail contact area [21]. The slip controllers are based on a model of the contact area, 
and an adaptive sliding mode controller is used for the control. However, the method was not verified.

The general description of the slip controllers group is depicted in Fig. 5. The slip controller input is a required torque that is set by a train driver. The required torque is multiplied by a slip controller output value that is in a range from zero to one. Therefore, the slip controller can only limit the value. The decreased required torque is led to a torque controller block, and then to an electric drive block. The electric drive block output is measured motor or wheel velocity $\mathrm{v}$ and calculated motor torque. The motor torque is calculated by a motor controller. The torque and the velocity are led to the estimator block that estimates force. Then, a derivative is calculated. If the Kalman filter is used, the derivative cannot be calculated because the slope is the output of the Kalman filter. The PI controller output maintains the required torque value to be the PI controller input equal to zero or positive. The positive value is used more often to avoid the operating point oscillates around the maximum point. When the PI controller input is maintained at a positive value, the operating point is located in the stable area of the adhesion characteristic.

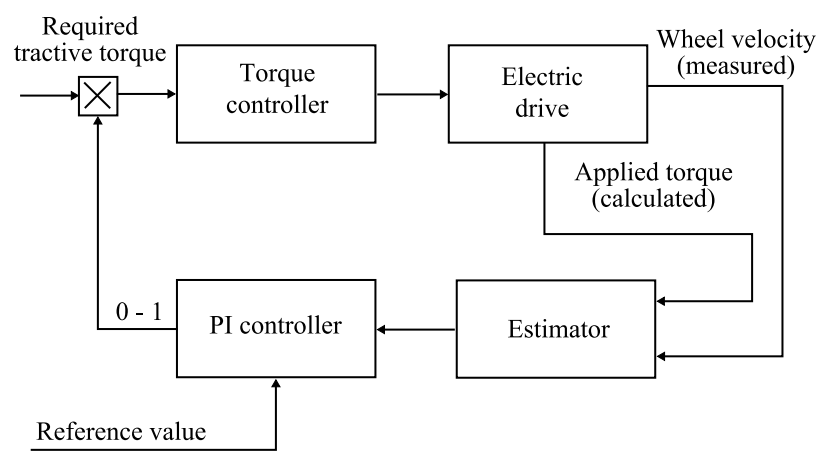

Fig. 5 General principle of the slip controller that estimates adhesion characteristic slope by estimator

The second approach is based on the measuring of the phase shift between the signal injected to the electric motor torque and its representation measured on wheel or motor angular velocity. The slip controller was initially presented in papers [13] and [22]. The slip controller requires adding a small periodic excitation torque signal to the required motor torque. The excitation torque causes oscillations of the motor torque and correspondingly angular speed. Between the motor torque oscillations and motor angular speed, a phase shift occurs. The phase shift is proportional to the actual adhesion characteristic slope. The principle of the slip controller is simple. The wheelset with electric drive creates a mechanical system with eigenfrequencies, and its poles are located in a stable position. However, the adhesion brings to the system additional damping that depends on the operating point position on the adhesion characteristic [23]. The additional damping changes the mechanical system parameters and causes the phase shift. The slip controller principle is described in [9].

The method general block diagram is depicted in Fig. 6. The block contains a generator of the excitation signal that is led to the electric drive. Basically, the signal can be added to the required torque in any part of the diagram. The applied torque and measured velocity are led to the angle calculation block diagram, and its output is led to the controller.

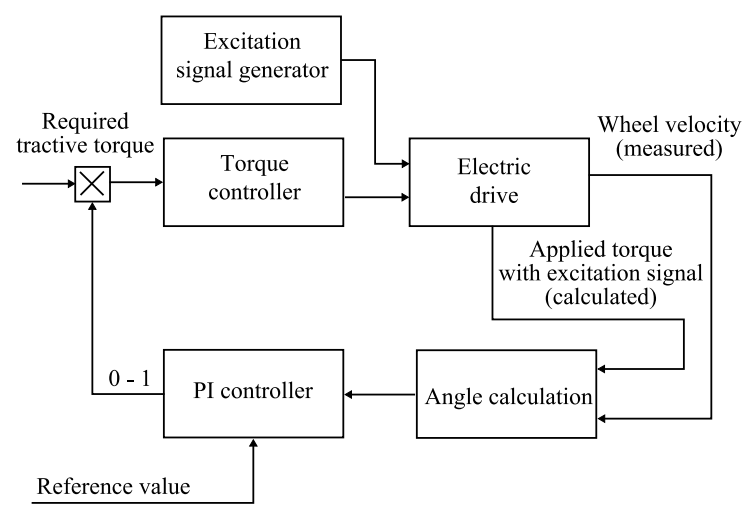

Fig. 6 General principle of the slip controller that estimates adhesion characteristic slope phase shift between torque and velocity

\section{SIMULATION RESULTS}

Simulation results for selected slip controllers for dry and wet rails are depicted in Fig. 7 and Fig. 8 respectively. The upper part of the figures depicts forces, and bottom part depicts velocities. The adhesion force is used as a basement that represents the highest possible achievable adhesion. The applied tractive forces have to be below the adhesion force to avoid slippage creation and the distance from the adhesion force is expresses regulatory quality of the slip controller. The adhesion force decreases at time 3 second and then starts to increase to the original value. The slip controller reaction in this part is crucial for comparison of the slip controller reaction. The figures compare the slip controller that estimates the slope of the adhesion characteristic with the method that keeps the slip velocity at the constant value. The slip controllers that determine the slope of the adhesion characteristic is based on the Kalman filter (marked as KF in the legend), disturbance observer (marked as DO) and phase shift (marked as phase).

Simulation results for dry rails are depicted in Fig. 7. All tractive forces are below the adhesion force. The highest tractive force and thus, the highest adhesion utilisation have the slip controller based on the phase shift determination and slip controller that control slip velocity to the constant value. However, the slip controller that determines the phase shift has the highest slip velocity that increases the wear of the wheels and rails. Although the slip controller has the best results, the controller should be set to have a lower slip velocity, and the results would be similar to the slip controller based on the Kalman filter. Note that there is a visible excitation signal on the torque and velocity of the slip controller that determines the slope of the adhesion characteristic from the phase shift.

Simulation results for wet rails are depicted in Fig. 8. The best results in the case produce the slip controller based on the Kalman filter because it has the highest average force with low slip velocity. The slip controller that controls the slip velocity has the worst results because the maximum point of the adhesion characteristic is located at higher slip velocity, and the slip controller cannot utilise the available adhesion. 

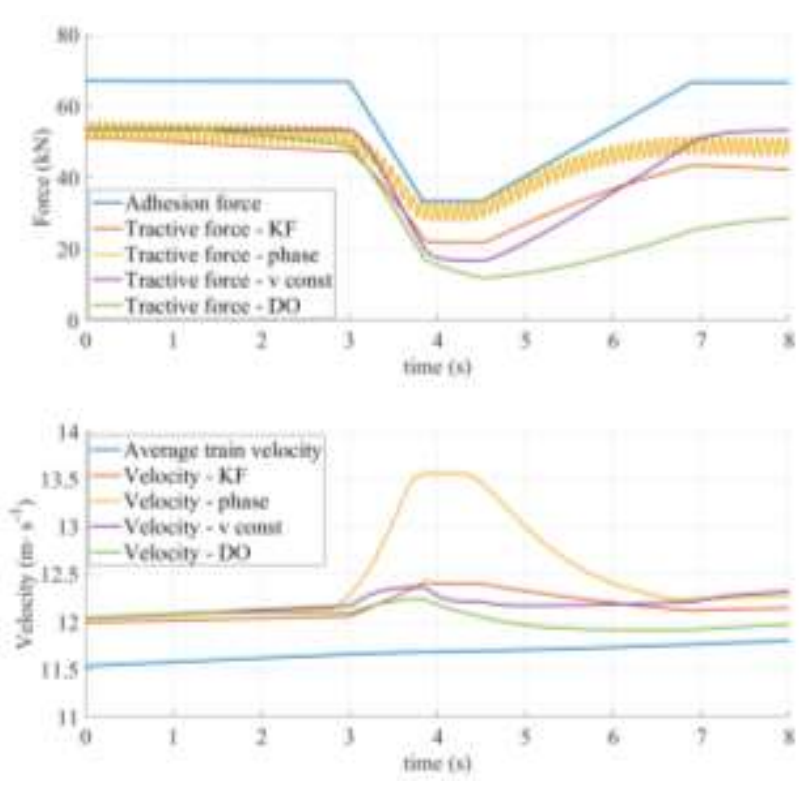

Fig. 7 Simulation results of selected slip controllers for dry rails
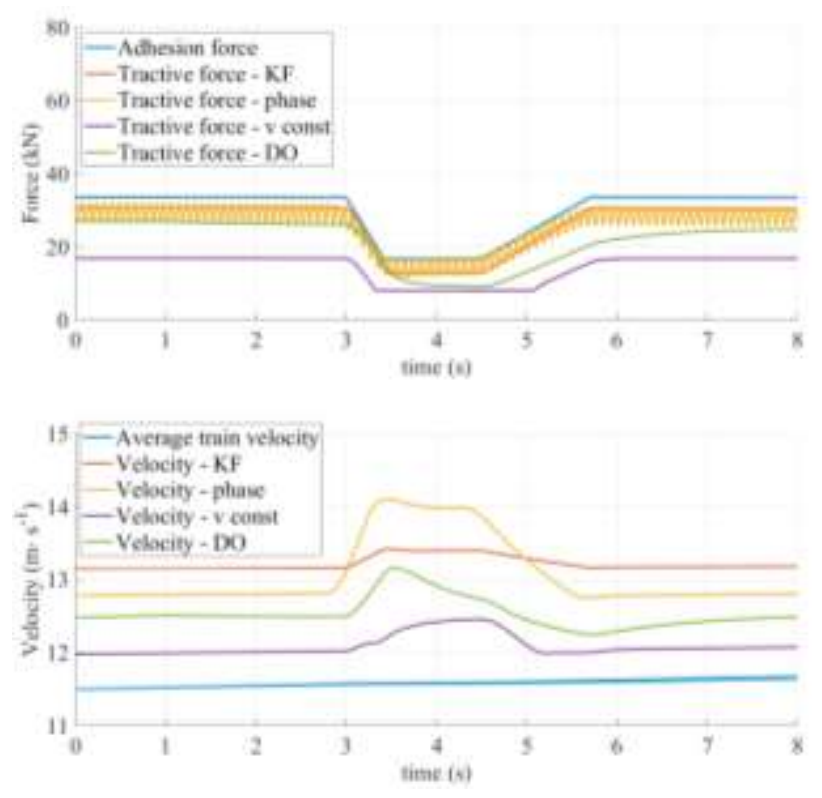

Fig. 8 Simulation results of selected slip controllers for wet rails

\section{CONCLUSIONS}

The slip controllers are a crucial part of railways traction vehicles because they enable to reach high tractive effort and speed during all conditions. Moreover, the slip controllers increase the economy of operation by decreasing wear of wheels and rails and can avoid train delay. The paper summarises developed approaches to slip control. The slip controllers were gradually developed from simple methods that were only protection or control the slip velocity to the constant value to the modern slip controllers based on complicated algorithms. The slip control is inseparable from the adhesion. Therefore, the paper starts with the description of the adhesion and its relation to wheel slip. Then, the existing slip controllers are sorted into groups. The methods based on the detection of the slope of the adhesion slip characteristic. However, from the simulation results, it is clear that the estimation has to be made by a stochastic filter, e.g.
Kalman filter or method that must change complete locomotive control.

\section{ACKNOWLEDGMENT}

This work was supported by the Technology Agency of the Czech Republic under the grant No. TE02000103, Center for Intelligent Drives and Advanced Machine Control.

\section{REFERENCES}

[1] I. Hussain, T. X. Mei, and R. T. Ritchings, "Estimation of wheelrail contact conditions and adhesion using the multiple model approach", Vehicle System Dynamics, vol. 51, no. 1, pp. 32-53, Jan. 2013. Doi: https://doi.org/10.1080/00423114.2012.708759

[2] X. Cao et al., "The effect of alumina particle on improving adhesion and wear damage of wheel/rail under wet conditions", Wear, vol. 348-349, pp. 98-115, Feb. 2016. Doi: 10.1016/j.wear.2015.12.004

[3] R. I. Popovici "Adhesive in Wheel - Rail Contacts," Ph.D. dissertation, Univ. of Twente, Enschede, The Netherlands, 2010.

[4] T. Watanabe, "Anti-slip Readhesion Control with Presumed Adhesion Force. Method of Presuming Adhesion Force and Running Test Results of High Speed Shinkansen Train,” Quarterly Report of Railway Technical Research Institute, QR of RTRI, vol. 41, No. 1, Mar 2000. Doi: https://doi.org/10.2219/rtriqr.41.32

[5] K. Kondo, "Anti-slip Control Technologies for the Railway Vehicle Traction". 2012 IEEE Vehicle Power and Propulsion Conference, Seoul, Korea, 2012, pp. 1306-1311. Doi: 10.1109 /VPPC.2012.6422493

[6] Wheel-rail interface handbook, 1 st Ed., CRC Press, Cambridge, 2009.

[7] L. Diao, L. Zhao, Z. Jin, L. Wang and S. M. Sharkh, "Taking Traction Control to Task: High-Adhesion-Point Tracking Based on a Disturbance Observer in Railway Vehicles," in IEEE Industrial Electronics Magazine, vol. 11, no. 1, pp. 51-62, March 2017. Doi: 10.1109/MIE.2016.2644699

[8] K. Xu, G. Xu, and C. Zheng, "Novel determination of Wheel-Rail adhesion stability for electric locomotives", Int. J. Precis. Eng. Manuf., vol. 16, no. 4, pp. 653-660, Apr. 2015.

Doi: https://doi.org/10.1007/s12541-015-0087-0

[9] P. Pichlik and J. Zdenek, "Overview of slip control methods used in locomotives", Transaction on Electrical Engineering, Vol.3, No.2, 2014.

[10]J.n Huang, J. Xiao and H. Weiss, "Simulation study on adhesion control of electric locomotives based on multidisciplinary virtual prototyping," 2008 IEEE International Conference on Industrial Technology, Chengdu, 2008, pp. 1-4.

Doi: $10.1109 /$ ICIT.2008.4608616

[11]W. Lin, Z. Liu, L. Diao, G. Zhang, D. Chen and Z. Li, "Maximum Adhesion Force Control Simulated Model of Electric Locomotive," 2007 IEEE International Conference on Automation and Logistics, Jinan, 2007, pp. 1704-1708. Doi: 10.1109/ICAL.2007.4338847

[12] S. Wang, J. Xiao, J. Huang, and H. Sheng, "Locomotive wheel slip detection based on multi-rate state identification of motor load torque, " Journal of the Franklin Institute, vol. 353, no. 2, 2016, pp. 521-540. Doi: https://doi.org/10.1016/j.jfranklin.2015.11.012

[13]R. Schreiber and P. Kögel "Identifikationsmethode zur Bestimmung der Adhäsion zwischen Rad und Schiene," (in German), ZEV GA. vol. 120, no. 2, p. 48-54, 1996.

[14]T. X. Mei and I. Hussain, "Detection of wheel-rail conditions for improved traction control," IET Conference on Railway Traction Systems (RTS 2010), Birmingham, 2010, pp. 1-6. Doi: $10.1049 /$ ic. 2010.0036

[15]M. Buscher, R. Pfeiffer and H. J. Schwartz, "Radschlupfregelung für Drehstromlokomotiven," (in German), EB. vol. 91, no. 5, p. 163-178 1993

[16]R. Stock, L. Stanlake, C. Hardwick, M. Yu, D. Eadie, R. Lewis, "Material concepts for top of rail friction management Classification, characterisation and application" Wear, vol. 366367, 2016, pp. 225-232.

Doi: https://doi.org/10.1016/j.wear.2016.05.028 
[17]M. Spiryagin, K. S. Lee and H. H. Yoo, "Control system for maximum use of adhesive forces of a railway vehicle in a tractive mode“, Mechanical Systems and Signal Processing, vol. 22, no. 3, 2008, pp. 709-720.

Doi: https://doi.org/10.1016/j.ymssp.2007.09.018

[18] J. Huang, J. Xiao, D. Zhao and S. Wang, "A wheel slip detection method of electric locomotive based on time-frequency analysis," 17th International IEEE Conference on Intelligent Transportation Systems (ITSC), Qingdao, 2014, pp. 1221-1225.

Doi: 10.1109/ITSC.2014.6957854

[19] K. Ohishi, Y. Ogawa, I. Miyashita and S. Yasukawa, "Anti-slip readhesion control of electric motor coach based on force control using disturbance observer," Conference Record of the 2000 IEEE Industry Applications Conference. Thirty-Fifth IAS Annual Meeting and World Conference on Industrial Applications of Electrical Energy (Cat. No.00CH37129), Rome, 2000, pp. 1001-1007 vol.2. Doi: $10.1109 /$ IAS.2000.881954

[20]P. Pichlík. "Comparison of Different Kalman Filters Types Performance for a Locomotive Slip Control Purposes" Poster 2017. Prague: CTU in Prague, 2017

[21]S. H. Park, J. Kim, J. J.Choi and H. Yamazaki, "Modeling and control of adhesion force in railway rolling stocks," Control Systems, IEEE, vol.28, no.5, pp.44-58, October 2008. Doi: 10.1109/MCS.2008.927334

[22] R. Schreiber, P. Kögel, P. Häse, and P. Hildenbrand, "Regelung zur optimalen Kraftschlußausnutzung bei Drehstromlokomotiven auf der Basis der Steigung der Kraftschlußkennlinie," (in German), EB, vol. 93 , no. 5 , p. 157-173, 1995

[23] J. Liu, H. Zhao, and W. Zhai, 'Mechanism of self-excited torsional vibration of locomotive driving system', Front. Mech. Eng. China, vol. 5 , no. 4 , pp. 465-469, Dec. 2010

Doi: https://doi.org/10.1007/s11465-010-0115-9 